\title{
COMMENTARY
}

\section{Pharmaceutical opioid use and harm in Australia: The need for proactive and preventative responses}

\author{
Briony Larance ${ }^{1}$, Louisa Degenhardt ${ }^{1,2,3,4}$, Amy Peacock ${ }^{1}$, Natasa Gisev ${ }^{1}$, Richard Mattick ${ }^{1}$, \\ Samantha Colledge ${ }^{1}$, Gabrielle Campbell ${ }^{1}$
}

1. National Drug and Alcohol Research Centre, UNSW Australia, Sydney, Australia

2. School of Population and Global Health, University of Melbourne, Melbourne, Australia

3. Murdoch Children's Research Institute, Melbourne, Australia

4. Department of Global Health, School of Public Health, University of Washington, Seattle, USA

Keywords: pharmaceutical opioids, opioid overdose, opioid mortality, opioid utilisation

Corresponding author: Briony Larance, Senior Research Fellow, National Drug and Alcohol Research Centre, University of New South Wales, e: b.larance@unsw.edu.au, t: +61 29385 0333, f: +61293850222.

This is the author manuscript accepted for publication and has undergone full peer review but has not been through the copyediting, typesetting, pagination and proofreading process, which may lead to differences between this version and the Version of Record. Please cite this article as doi: $10.1111 /$ dar.12617

This article is protected by copyright. All rights reserved. 


\begin{abstract}
There are parallels between the North American experience of escalating pharmaceutical opioid utilisation and harm, and the trends being observed in Australia. In Australia, opioid utilisation has increased dramatically over the past two decades. There have been significant shifts away from the predominant prescribing of "weak" and short-acting opioids, to "strong" and long-acting opioids, for an increasing range of chronic pain indications. In concordance with escalating use, Australia is experiencing increases in opioid-related hospital admissions and overdose, as well as opioid dependence and treatment-seeking. Despite increasing concern regarding pharmaceutical opioid use and harms in Australia, responses have been limited. There have been no recent changes in regulatory systems for prescription-only pharmaceutical opioids, opioid prescribing guidelines, limits on doctors' prescribing, monitoring of patient or doctor access to opioids, or in access to medicines via public subsidy. Potentially abuse-deterrent opioid formulations have entered the Australian market, with studies suggesting that these formulations are less likely to be tampered with by people who inject drugs, but to date, there have been limited impacts on opioid utilisation and harm. Additional strategies may include enhancing access to effective approaches to pain management and opioid dependence, and scaling-up naloxone provision. There is a unique opportunity for a proactive and preventative response to pharmaceutical opioids in Australia, to avoid experiencing the scale of problems seen elsewhere.
\end{abstract}

This article is protected by copyright. All rights reserved. 
The North American experience of escalating pharmaceutical opioid use and harm is sobering. Fischer and Rehm (2017) describe an unprecedented "public health crisis" of pharmaceutical opioid use and dependence [1], with substantial increases in opioid-related deaths [2], transition to heroin use [3], and strain upon the health and drug treatment system [4]. The problems observed across North America appear to have been driven by widespread prescribing of controlled-release and "strong opioids", such as oxycodone and fentanyl [5].

Increasing opioid exposure across the general population in these countries has continued, despite implementation of various initiatives that have limited evidence of effectiveness [6]. Strategies to address over-prescribing of riskier opioids have included tighter regulation [6], legislation addressing rogue pain management clinics where opioids were inappropriately prescribed and dispensed on a large scale [7], targeting prescribing behaviour [8], and development of "abuse deterrent" formulations [9]. Furthering the crisis, new opioid dependent populations have been transitioning from pharmaceutical opioid use to heroin use and injecting [3]. In 2016, the United States (US) government responded by providing an additional USD\$1.1billion to expand opioid dependence treatment. This is one step in addressing the harms of risky opioid use and dependence, but recent media reports indicate that continued funding at this level by the Trump administration is uncertain [e.g. 10].

There are serious concerns that Australia is experiencing similar trends in increasing use and harm [11]. Pharmaceutical opioid use increased 15-fold in Australia over the last two decades [12], and there is considerable utilisation of over-the-counter codeine [13]. Originally registered to manage cancer and acute pain , opioids have been approved to treat an increasing number of chronic non-cancer pain conditions [14]. There has also been a shift in the types of opioids prescribed. In 1990, 90\% of opioid dispensings were for "weak" opioids and almost all (96\%) were short-acting [14]. By 2011, 40\%of all dispensings were for "strong" and 50\% were for long-acting opioids [14]. In concordance with escalating use, there is evidence of increased opioid-related hospital admissions, overdose, dependence 
and treatment-seeking [15-19]. Pharmaceutical opioid cause over 70\% of opioid overdose fatalities in Australia, which is similar in the US [19].

Despite increasing concern regarding pharmaceutical opioid use and harms in Australia, no recent changes have occurred in regulations for prescription-only pharmaceutical opioids, prescribing guidelines, limits on prescribing, monitoring of patient or doctor access, or in access to medicines via public subsidy (Australians have government-subsidy for many medicines). Implementation of a real-time opioid prescription monitoring system in one jurisdiction (Tasmania) is an exception (Note: Legislation for real time prescription monitoring in Victoria was introduced into the Victorian Parliament in August 2017); however, participation is voluntary, uptake by pharmacies and prescribers has been limited and the initiative is yet to undergo a formal evaluation [20].

Australia is also approving an increasing array of potentially abuse-deterrent opioid formulations [21]. In Australia, available evidence from convenience samples suggests most individuals tampering with pharmaceutical opioids (i.e. physically manipulating tablets to prepare them for unintended routes of administration, such as snorting or injecting) take these drugs via injection, on an infrequent basis, and use a variety of pharmaceutical opioids and heroin [21]. In contrast, tampering for non-injecting routes of administration is more common in North America [22]. Australian post-marketing surveillance studies show reductions in use and tampering amongst people who inject drugs following introduction of abuse-deterrent formulations, with no evidence of switching to other pharmaceutical opioids or heroin $[21,23]$. However, these formulations have not eradicated tampering and injection, and have had limited impacts on opioid utilisation and population-level harm [21].

Socioeconomic disadvantage and mental health comorbidity appear strongly correlated with higher opioid utilisation rates [24] and problematic opioid use and dependence [25]. Mirroring US studies [e.g. 26], there is substantial geographic variation in opioid use and related mortality and morbidity in Australia, with higher utilisation rates observed in areas 
outside of major cities for all types of opioids $[13,15,24,27]$. This may be in part related to a lack of alternative pain treatment options in geographically remote areas. Australian studies indicate that people living with chronic non-cancer pain in rural and remote areas report a lack of access to pain specialists and financial barriers to pain treatment, compared with people from urban areas [28].

Given increased prescribing, lack of regulatory change to prescription-only pharmaceutical opioids, and potentially limited impact of abuse-deterrent products, we are led to question why Australia has not experienced the same rapid escalation in opioid-related harms evident in North America. A number of factors are likely to be important. Australia's universal healthcare system provides some protection; there are wide and significant disparities in healthcare access between US adults with above and below-average incomes, which persist after controlling for insurance coverage, race/ethnicity, immigration status and other important factors [29]. There is a long history of direct-to-consumer advertising of pharmaceuticals in the US, whereas advertising in Australia is more restricted [30]. There are also differences in harm reduction and drug treatment responses: both opioid substitution therapy and needle and syringe programme coverage are far higher in Australia relative to the US [31].

Nonetheless, there are multiple lessons to be learnt from the North American experience. Despite escalating rates of use and repeated calls for concern, with the exception that codeine will no longer be available over-the-counter from 2018 [32], we have not yet seen any subsequent regulatory, policy or programmatic shifts in Australia. Given the abundance of data sources on pharmaceutical and illicit drug use and harms within Australia, there is a unique opportunity to maximise the utility of existing administrative and routinely-collected data, and monitor changes in pharmaceutical opioid use and harms, as well as other drugs more broadly [e.g. 33]. Regulatory controls on prescribing are likely to be one part of the solution, but it is clear that a more comprehensive and multi-faceted approach is needed. Additional strategies include enhancing access to effective, multidisciplinary approaches to 
pain management and comorbidity, developing more attractive and accessible options for the treatment of opioid dependence [31], and scaling-up the provision of take-home naloxone for people using prescribed and illicit opioids. Australia is in a fortunate position; we have the opportunity for a proactive and preventative response to pharmaceutical opioids, to avoid experiencing the scale of problems seen elsewhere.

This article is protected by copyright. All rights reserved. 


\section{References}

1. Fischer B, Rehm J. Revisiting the 'paradigm shift' in opioid use: Developments and implications 10 years later. Drug Alcohol Rev 2017 [Epub ahead of print].

2. Kassebaum NJ, Arora M, Barber RM, Bhutta ZA, Brown J, Carter A, et al. Global, regional, and national disability-adjusted life-years (DALYs) for 315 diseases and injuries and healthy life expectancy (HALE), 1990-2013: a systematic analysis for the Global Burden of Disease Study 2015. Lancet 2016;388:1603-58.

3. Banerjee G, Edelman EJ, Barry DT, Becker WC, Cerda M, Crystal S, et al. Non-medical use of prescription opioids is associated with heroin initiation among US veterans: a prospective cohort study. Addiction 2016;111:2021-31.

4. Hsu DJ, McCarthy EP, Stevens JP, Mukamal KJ. Hospitalizations, costs and outcomes associated with heroin and prescription opioid overdoses in the United States 200112. Addiction;112:1558-64.

5. Rudd RA, Seth P, David F, Scholl L. Increases in drug and opioid-involved overdose deaths - United States, 2010-2015. MMWR Morb Mortal Wkly Rep2016;65:1445-52.

6. Wickramatilake S, Zur J, Mulvaney-Day N, Klimo MCv, Selmi E, Harwood H. How states are tackling the opioid crisis. Public Health Reports 2017;132:171-9.

7. Chang H-Y, Lyapustina T, Rutkow L, Daubresse M, Richey M, Faul M, et al. Impact of prescription drug monitoring programs and pill mill laws on high-risk opioid prescribers: A comparative interrupted time series analysis. Drug Alcohol Depend 2016;165:1-8.

8. Dowell D, Haegerich TM, Chou R. CDC Guideline for Prescribing Opioids for Chronic Pain--United States, 2016. JAMA 2016;315:1624-45.

9. Food and Drug Administration. Abuse-Deterrent Opioids - Evaluation and Labeling. 2015.

10. Sun LH, Higham S. Trump proposes steep cuts to White House 'drug czar' office amid opioid crisis. The Washington Post. 5 May 2017.

11. Berterame S, Erthal J, Thomas J, Fellner S, Vosse B, Clare P, et al. Use of and barriers to access to opioid analgesics: a worldwide, regional, and national study. Lancet 2016;387:1644-56.

12. Blanch B, Pearson SA, Haber PS. An overview of the patterns of prescription opioid use, costs and related harms in Australia. Br J Clin Pharmacol 2014;78:1159-66.

This article is protected by copyright. All rights reserved. 
13. Gisev N, Nielsen S, Cama E, Larance B, Bruno R, Degenhardt L. An ecological study of the extent and factors associated with use of prescription and over-the-counter codeine in Australia. Eur J Clin Pharmacol 2016;72:469-94.

14. Karanges EA, Blanch B, Buckley N, Pearson SA. Twenty-five years of prescription opioid use in Australia: A whole-of-population analysis using pharmaceutical claims. Br J Clin Pharmacol 2016;82:255-67.

15. Berecki-Gisolf J, Hassani-Mahmooei B, Clapperton A, McClure R. Prescription opioid dispensing and prescription opioid poisoning: Population data from Victoria, Australia 2006 to 2013. Aust N Z J Public Health 2017;41:85-91.

16. Degenhardt L, Black E, Breen C, Bruno R, Kinner S, Roxburgh A, et al. Trends in morphine prescriptions, illicit morphine use and associated harms among regular injecting drug users in Australia. Drug Alcohol Rev 2006;25:403-12.

17. Nielsen S, Roxburgh A, Bruno R, Lintzeris N, Jefferson A, Degenhardt L. Changes in non-opioid substitution treatment episodes for pharmaceutical opioids and heroin from 2002 to 2011. Drug Alcohol Depend 2015;149:212-9.

18. Roxburgh A, Bruno R, Larance B, Burns L. Prescription of opioid analgesics and related harms in Australia. Med J Aust 2011;195:280-4.

19. Roxburgh A, Hall W, Dobbins T, Gisev N, Burns L, S. P, et al. Trends in heroin and pharmaceutical opioid overdose deaths in Australia. Drug Alcohol Depend. 2017;179:291-8.

20. Shand F, Campbell G, Hall WD, Lintzeris N, Cohen M, Degenhardt L. Real-time monitoring of Schedule 8 medicines in Australia: evaluation is essential. Med J Aust 2013;198:80-1.

21. Degenhardt L, Bruno R, Ali R, Lintzeris N, Farrell M, Larance B. The introduction of a potentially abuse deterrent oxycodone formulation: Early findings from the Australian National Opioid Medications Abuse Deterrence (NOMAD) study. Drug Alcohol Depend 2015;151:56-67.

22. Cassidy TA, DasMahapatra P, Black RA, Wieman MS, Butler SF. Changes in prevalence of prescription opioid abuse after introduction of an abuse-deterrent opioid formulation. Pain Med 2014;15:440-51.

23. Larance B, Degenhardt L, Lintzeris N, Bell J, Winstock A, Dietze P, et al. Postmarketing surveillance of buprenorphine-naloxone in Australia: Diversion, injection and adherence with supervised dosing. Drug Alcohol Depend 2011;118:265-73.

This article is protected by copyright. All rights reserved. 
24. Degenhardt L, Gisev N, Cama E, Nielsen S, Larance B, Bruno R. The extent and correlates of community-based pharmaceutical opioid utilisation in Australia. Pharmacoepidemiol Drug Saf. 2016;25:521-38.

25. Campbell G, Nielsen S, Larance B, Bruno R, Mattick R, Hall W, et al. Pharmaceutical opioid use and dependence among people living with chronic pain: associations observed within the Pain and Opioids in Treatment (POINT) Cohort. Pain Med 2015;16:1745-58.

26. King NB, Fraser V, Boikos C, Richardson R, Harper S. Determinants of increased opioid-related mortality in the United States and Canada, 1990-2013: a systematic review. Am J Public Health. 2014;104:e32-e42.

27. Rintoul AC, Dobbin MDH, Drummer OH, Ozanne-Smith J. Increasing deaths involving oxycodone, Victoria, Australia, 2000-09. Inj Prev 2011;17:254-9.

28. Peacock A, Nielsen S, Bruno R, Campbell G, Larance B, Degenhardt L. Geographic variation in health service use and perceived access barriers for Australian adults with chronic non-cancer pain receiving opioid therapy. Pain Med 2016;17:2003-16.

29. Hardie E, Critchley C. Public perceptions of Australia's doctors, hospitals and health care systems. Med J Aust 2008;189:210-4.

30. Mansfield PR, Mintzes B, Richards D, Toop L. Direct to consumer advertising: Is at the crossroads of competing pressures from industry and health needs. BMJ 2005;330:56.

31. Mathers BM, Degenhardt L, Ali H, Wiessing L, Hickman M, Mattick RP, et al. HIV prevention, treatment, and care services for people who inject drugs: a systematic review of global, regional, and national coverage. Lancet 2010;375:1014-28.

32. Cairns R, Brown JA, Buckley NA. The impact of codeine re-scheduling on misuse: a retrospective review of calls to Australia's largest poisons centre. Addiction 2016;111:1848-53.

33. National Institute on Drug Abuse. National Drug Early Warning System (NDEWS) University of Maryland 2016. Available from: https://www.drugabuse.gov/relatedtopics/trends-statistics/national-drug-early-warning-system-ndews.

This article is protected by copyright. All rights reserved. 


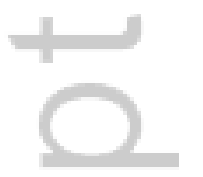

This article is protected by copyright. All rights reserved. 


\section{University Library}

\section{- M M N E R VA A gateway to Melbourne's research publications}

Minerva Access is the Institutional Repository of The University of Melbourne

Author/s:

Larance, B;Degenhardt, L;Peacock, A;Gisev, N;Mattick, R;Colledge, S;Campbell, G

Title:

Pharmaceutical opioid use and harm in Australia: The need for proactive and preventative responses

Date:

2018-04-01

Citation:

Larance, B., Degenhardt, L., Peacock, A., Gisev, N., Mattick, R., Colledge, S. \& Campbell, G. (2018). Pharmaceutical opioid use and harm in Australia: The need for proactive and preventative responses. DRUG AND ALCOHOL REVIEW, 37, pp.S203-S205. https:// doi.org/10.1111/dar. 12617.

Persistent Link:

http://hdl.handle.net/11343/293573 